\title{
AS SANTAS ANAS, OS JOGOS DE PODER E A MEMÓRIA COLETIVA DA BARRIGUDA
}

\author{
AS SANTAS ANAS, THE GAMES OF POWER \\ AND THE COLLECTIVE MEMORY OF BARRIGUDA
}

\author{
Tâmara Rossene Andrade Bomfim ${ }^{62}$ \\ Edil Silva Costa ${ }^{63}$
}

\begin{abstract}
RESUMO: Este estudo se baseia nas narrativas da comunidade da Barriguda, município de Ibotirama - BA, sobre a história da Escrava Ana, reconhecida, pela crença popular, como Santa, creditando a sua transformação ao martírio e sofrimento vividos, aos maus tratos do seu Senhor, devido à escrava ter engravidado e dado à luz a um filho, sem a sua permissão. Testemunhos, depoimentos e relatos de diferentes gerações mantêm viva a memória coletiva sobre a Santa Ana, que também atrai peregrinos de outras regiões. A igreja, ao que parece, procura dissuadir a crença na figura da escrava pobre, negra, subalternizada e marginalizada e, em seu lugar, oferece aos seus devotos a figura consolidada de outra Ana, Santa canonizada, legitimada, com uma aparência que em nada lembra a figura imaginária da escrava, representativa da Sagrada Família e da hegemonia da Igreja sobre os seus fiéis. Esse cenário faz ressurgir questionamentos que se relacionam aos sentidos criados pelos habitantes do lugar para as diferentes Anas, sobre a (re)existência da Ana vulnerável, o polo mais fragilizado no jogo de poder que se sustém sobre qual das Anas traz o reflexo da identidade da população local, também periférica e marginalizada e sobre a luta travada para preservar a imagem da Escrava, existente apenas no imaginário das pessoas, em contraponto à imagem institucionalizada, registrada nos livros sagrados e nas esculturas. A base teórica se constrói a partir das obras de Michel Foucault (2015), Paul Zumthor (2010), Stuart Hall (2008) e Clifford Geertz (2008).
\end{abstract}

PALAVRAS-CHAVE: Memória. Identidade. Religiosidade popular.

\begin{abstract}
The study is based on the narratives of the community of Barriguda, municipality of Ibotirama $\mathrm{Ba}$, on the history of the Ana Slave, recognized by the popular belief as Santa, crediting his transformation, the martyrdom and suffering experienced, the mistreatment of his Lord, because the slave had become pregnant and given birth to a child, without his permission. Testimonies, testimonies and reports from different generations keep alive the collective memory about Santa Ana, which also attracts pilgrims from other regions. The church, it seems, seeks to dissuade the belief in the figure of the poor, black, subalternized and marginalized slave and, instead, offers its devotees the consolidated figure of another Anna, a canonized saint, legitimized, with an appearance that in nothing resembles the imaginary figure of the slave, representative of the Holy Family and the hegemony of the Church over its faithful. This scenario raises questions that relate to the senses created by the inhabitants of the place for the different Anas, about the (re) existence of the vulnerable Ana, the most fragile pole in the power game that sustains itself, on which of the Anas brings the reflection of the identity of the local population, also peripheral and marginalized, and the struggle to preserve the image of the Slave, existing only in the imaginary of the people, as opposed to the institutionalized image recorded in the sacred books and sculptures. The theoretical basis is built on the works of Michel Foucault (2015), Paul Zumthor (2010), Stuart Hall (2008) and Clifford Geertz (2008).
\end{abstract}

KEYWORDS: Memory. Identity. Popular religiosity.

\section{Introdução: uma narrativa, muitas vozes}

Dona Dove sobre os degraus da cozinha, com seus noventa e seis anos, segurando em um pedaço de pau que utiliza para se apoiar, deixa atrás de si o grande quintal, com as galinhas livres e alimentadas. Pela janela que se abre, a serra com pontos brancos, o céu muito azul e uma brisa fresca, percorro os olhos pela cozinha que se alcança descendo dois ou três

\footnotetext{
${ }^{62}$ Mestre em Crítica Cultural pelo Programa de Pós Graduação em Crítica Cultural, Universidade do Estado da Bahia (Póscrítica/UNEB). Endereço eletrônico: tamarabomfim@hotmail.com.

${ }^{63}$ Doutora em Comunicação e Semiótica (PUC-São Paulo), Professora Titular da Universidade do Estado da Bahia, Campus de Alagoinhas. Endereço eletrônico: escosta@uneb.br.
} 
degraus, avisto um fogão a lenha e outra janela que se oferece, para a vida que corre nos fundos da casa. Passo por uma parede da sala, com fotografias antigas, cujos personagens me encaram. Começo a pensar na história que me levou até aquele lugar, uma memória da minha infância, que eu julgara perdida, mas que a curiosidade me levou a encontrar o fio da meada para resgatá-la. Um barulho de madeira envelhecida cedendo me desperta do pensamento longínquo. Dona Dove senta-se a minha frente, com dificuldade. Meu olhar é então desviado para ela, que começa a me contar a história da Santa Ana ou Defunt'Ana, como alguns a chamam, da qual acabo de visitar o túmulo, dali a menos de um quilômetro. A história é do tempo em que Ibotirama era cortada por levas de animais, atravessando os seus domínios. No tempo em que os vapores singravam as águas do rio São Francisco. Por ali, Senhores poderosos eram proprietários de muitos escravos. Ela ensaia um sorriso, mas não chega a esboçá-lo e diz que ouviu a história do seu pai e que o seu avô também a contava e que, de lá para cá, já se passaram muitos anos. Olha para o alto, como se tentasse calcular o tempo decorrido, mas desiste. Ana era uma escrava que morava naquelas bandas e cometeu um crime muito grave, aos olhos do homem que detinha a sua posse. Ana cometeu o bárbaro crime de engravidar. O dono de Ana não perdoou o seu erro e tratou de escrever a sua sentença ${ }^{64}$.

Imagino quem seria o pai do filho de Ana. Se o seu filho seria de algum escravo, que teria se encantado com a sua beleza, se teria engravidado de algum filho do seu Senhor, ou do seu próprio dono, que não esperava aquele desfecho. Não se sabe ao certo, quantos anos se passaram até que Ana pudesse cumprir o que lhe fora destinado. Mas o seu filho já havia nascido e já era um pouco crescido. A mando do Senhor, dono de Ana, abrem um buraco e jogam nele centenas de formigas de fogo, que, logo mais, se alimentariam da carne da pobre escrava. Ana é morta pelas picadas dos insetos, agonizando calada até que o seu destino se cumprisse. O seu corpo estaria entregue ao relento, embora a paisagem da Barriguda tenha uma aura de encantamento, com as suas serras e o vento que em alguns períodos não cessa. $\mathrm{O}$ seu filho the arrastou o corpo e o colocou sobre um pedaço de couro, levando-o para ter um sepultamento justo, como qualquer alma deste mundo mereceria. Cava então a cova da mãe, que o alimentou e o amou. Ali deposita a sua dor e o corpo de Ana e passa a peregrinar para aquele local, com suas rezas e seu lamento, algumas vezes, ao longo dos dias.

Poucos dias se passaram e quando o menino parte para mais uma hora de prantear a sua mãe, é tomado por um susto enorme. A cova jaz aberta e vazia. Fica confuso. Procura imaginar o que aconteceu para lhe tirarem a única coisa que lhe restara. A luz da manhã incide sobre um objeto que está na cabeceira da sepultura. Quase cego, vislumbra a imagem de uma santa, toda trabalhada em ouro. Fica tonto e deslumbrado. Cai ao lado da imagem, sem entender. Onde estará a sua mãe? Será que a sua sina já não teria se cumprido? Não bastava ter sido devorada pelas formigas, agora some também o seu corpo? Onde mais terá abrigo aquele filho órfão, já que não mais lhe resta o cadáver daquela a quem devia a vida? Apavorado, toma a imagem em seus braços. Ela é linda, assim como fora a escrava Ana. Correndo assustado pelo matagal, o garoto vai atrás do padre da comunidade.

Dona Dove para nesse ponto e olha para as folhas que se balançam do lado de fora da casa, embaladas pelo vento e diz: O Padre disse ao menino-que Ana virou Santa. Um silêncio percorre a sala e eu fico imaginando o que acabara de ser dito. Ao meu lado, o meu avô e a minha mãe, que eu levara para descortinar aquela história, tem os olhos fixos na Senhora, cujos olhos agora faíscam. Uma Santa toda de ouro, com uma coroa cravada de pedras preciosas. Mas o Padre levou a Santa para a Igreja da Penha, a Santa Ana, a nossa Santa Ana. E nunca mais a trouxeram de volta. E depois disso, colocaram um cruzeiro de madeira na sepultura. Ana, desde aquele dia, tem realizado muitos milagres. Vem gente de todos os

\footnotetext{
${ }^{64}$ Para destacar as falas transcritas dos entrevistados, utilizaremos a fonte em itálico.
} 
lugares desse mundo soltar foguetes, acender velas e agradecer a Santa Ana pelas graças alcançadas. Por isso que construíram aquela capela, moça, perto do túmulo da escrava. E quando eu não estiver mais aqui para contar a história, meus filhos já acreditam nela e estarão aqui para contá-la. Todos nessa casa já fizeram promessas para ela e foram atendidos. Vixe, nem conto as vezes!

Nesse momento me lembro de mim mesma, ainda menina, andando pelo caminho que leva até o túmulo da Defunt'Ana. A minha avó Anália, à frente, levando velas e flores. Ouço o estampido dos foguetes. Não estamos sós. Junto conosco, vão o meu avô e algumas pessoas nos acompanhando. Lembro que foi por minha avó que conheci a história da escrava Ana. Olho para a velha Dove, meu avô e minha mãe, ali na mesma sala, e me sinto responsável por repassar adiante aos meus filhos o que ouvi. Um assombro me toma. E sigo pensando que acabo de descobrir o milagre da Santa Ana: é a história, que não cessa de ser contada. A trajetória da oralidade, que agora sussurra em meus ouvidos.

As minhas memórias se misturaram com as memórias de Dona Dove, uma Senhora nascida e criada na comunidade da Barriguda, filha de lavradores, que seguiu o ofício dos pais. Ao lado da sua casa, duas outras residências habitadas por duas filhas, ambas contando com mais de 70 anos. A história da Escrava que virou Santa veio à tona, quando eu realizava o trabalho de campo para a minha dissertação do mestrado, buscando informações sobre a cultura popular ribeirinha do Velho Chico. Eu me lembrava vagamente dessa história. Quando busquei entrevistar as pessoas da comunidade sobre a Santa Ana, as duas pessoas que procurei me disseram que Dona Dove era a pessoa mais velha daquele lugar e a mais indicada para fazer esse relato. Nenhuma delas soube dizer a quanto tempo a história existe. Dona Dove me disse ter ouvido do seu pai, quando ainda era menina e que ele, sim, havia conhecido o dono da escrava. Uma história que não foi escrita nem registrada por ninguém e que tem permanecido através da oralidade, me fazendo lembrar do traçado da voz, narrado por Paul Zumthor, quando afirma que,

Ela interpreta o sujeito, o constitui e nele imprime a cifra de uma alteridade. Para aquele que produz o som, ela rompe uma clausura, libera de um limite que por aí revela, instauradora de uma ordem própria: desde que é vocalizado, todo objeto ganha para um sujeito, ao menos parcialmente, estatuto de símbolo.

(ZUMTHOR, 2010, p. 15)

A voz daqueles que vêm narrando a saga da mulher negra, pobre e escravizada rompeu a clausura da comunidade isolada, do espaço desvalorizado que esse lugar ocupa na cadeia de produção, do tempo transcorrido e fixou a sua simbologia como uma Santa, que fugiu aos padrões tradicionais para ser santificada. A voz de Dona Dove, ultrapassando a palavra (ZUMTHOR, 2010, p. 11), protegendo a figura de Ana, assim como outras vozes, de outras épocas, que a trouxeram até aqui. Voltando a Paul Zumthor (2010, p.66).

O verbo, força vital, vapor do corpo, liquidez carnal e espiritual, no qual toda atividade repousa, se espalha no mundo ao qual dá vida. Na palavra tem origem o poder do chefe e da política, do camponês e da semente. O artesão que modela um objeto, pronuncia (e, muitas vezes, canta) as palavras, fecundando seu ato. Verticalidade luminosa brotando das trevas interiores, ainda marcada, todavia, por estes sulcos profundos, a palavra proferida pela Voz cria o que ela diz. Ela é justamente aquilo que chamamos poesia. Mas ela é também memória viva, tanto para o indivíduo (para quem a imposição do seu nome deu forma), quanto para o grupo, cuja linguagem constitui a energia ordenadora.

Assim, essa voz concedeu poder à pequena comunidade, através da Santa que continuou existindo na memória coletiva, como um tesouro protegido pela oralidade, se propagando pelo tempo. 
Mas o que há por trás da narrativa da Santa Ana Escrava? Quais os fios do contexto de produção e das relações entre a cultura popular ribeirinha que tecem sua malha intertextual? Que sentidos se constroem a partir de diversos discursos - o popular, o oficial, as narrativas de encantamento, o texto bíblico e as histórias de santos? Para além da realização de seus milagres, a Santa que tem por altar um túmulo, vítima da escravidão e do patriarcalismo, provoca a reflexão sobre a condição de mulheres, cujas narrativas vêm de longe e guardam traços de uma sociedade matriarcal. Assim, a narrativa da Barriguda é uma narração grávida de muitas outras narrativas.

\section{A comunidade da Barriguda, a escrava e as Santas Anas}

A Barriguda é uma comunidade da zona rural do município de Ibotirama, estado da Bahia, território do Velho Chico ${ }^{65}$, que fica a aproximadamente 30 (trinta) quilômetros da zona urbana. No histórico das cidades que se formaram nessa região, o rio São Francisco atuou, durante muito tempo para a população dos seus limites geográficos, como elemento aglutinador, reunindo em torno de si as diferentes camadas sociais e influenciado os seus estilos de vida. Às suas margens se configuravam relações de poder, na figura dos coronéis, dos escravos, da hierarquia desvelada nos postos de trabalho e nas embarcações. A figura do colonizador é descrita no vale do São Francisco em ciclos diversos, buscando novas formas de produção e de acumulação de riquezas. O ciclo do gado, do ouro e das pedras preciosas adentram as terras banhadas pelo rio. Assim, o rio tornou-se veículo de fusão de diferentes etnias e culturas, navegando através do seu curso. Junto com os exploradores, também chegaram os cantos, as danças, os ritos. A forma de organização social inicial na margem do Velho Chico, com o poder instituído dos coronéis, lembrava muito as organizações feudais. A igreja, outro centro de poder, com as missões empreendidas em terras ribeirinhas, foi se infiltrando no cotidiano da população subalternizada e dependente dos grandes Senhores de terra dessa região.

Da população massacrada pelas precárias condições de vida, com quase nenhuma possibilidade de transformação no plano material, apelar e acreditar na providência divina, buscar os caminhos da fé, era quase uma necessidade para continuar sobrevivendo. Acreditar que se as condições eram desiguais e que no plano espiritual era possível ter tratamento igualitário. Dessa forma, percebe-se que as tradições católicas estiveram presentes tanto na devoção à Santíssima Trindade e aos Santos, nos infortúnios das secas e das enchentes, quanto nos momentos de diversão e celebração, quando o culto ao Sagrado se atrelava ao Profano. O dedo do colonizador foi trazendo as suas crenças, que iam sendo diluídas no cotidiano dos colonizados, tomando para si esses elementos, como parte da construção de uma cultura híbrida, complexa, transformada nas lutas travadas entre dominadores e dominados, que se insurgiam ao processo hierárquico.

Assim, considerando que não existe uma cultura popular íntegra, autêntica e autônoma, situada fora do campo de força das relações de poder e de dominação culturais (HALL, 2003, p. 254), serão apresentadas algumas considerações sobre o processo de reconstrução dos discursos hegemônicos e que dão às narrativas das Santas Anas um caráter muito peculiar. Se o discurso do colonizador é predominante, tem que enfrentar o jogo de força com outros discursos que se impõem, costurados pelo viés da religiosidade popular.

\footnotetext{
${ }^{65}$ A região é cortada pelo rio São Francisco, chamado de forma carinhosa pelo apelido de Velho Chico, pelos ribeirinhos que habitam o seu território. O território do Velho Chico é formado por dezesseis municípios.
} 


\section{Considerações sobre a religiosidade popular}

A história da Escrava Ana ou Santa Ana ou Defunt'Ana é reflexo de uma situação cultural e social que só será compreendida se forem revisitadas as raízes de uma religião brasileira, nosso catolicismo popular. O processo colonizador usou estratégias muito eficientes para impor seu discurso como dominante. No Brasil, de modo semelhante com a América espanhola, o braço da coroa portuguesa que executou com competência o processo de aculturação foi o do padre jesuíta, forte aliado na expansão colonial, e que, em última instância, lutava também por sua própria sobrevivência, para se fazer útil e necessário ao poder político. Enquanto o Marquês de Pombal expulsava os jesuítas de Portugal, em nome de um estado laico, é nas colônias que eles se fortalecem como aliados importantes, tanto para acalmar os nativos e "protegê-los" da escravidão, evitando reações mais violentas, quanto para manter uma certa ordem entre homens que gozavam de liberdades nas colônias, o que não lhes seria possível na Metrópole. O Brasil se tornaria um paraíso de libertinagem que seduzia até mesmo os colonos mais religiosos.

Assim, a catequese do indígena e, posteriormente, a "conversão" dos negros escravizados, na maior parte das vezes limitada ao batismo, foram ações necessárias para a consolidação do projeto colonial. No entanto, percebendo as dificuldades na tarefa - já conhecida na Europa durante as tentativas de conversão de judeus e mouros - as estratégias precisavam ser mais enérgicas. Para isso foi necessário conhecer a religiosidade do nativo, sua língua e costumes, em especial seus medos. Fazer analogias dos mitos indígenas com o discurso católico foi uma das formas encontradas pelos jesuítas para envolver os "pagãos" e subjugá-los. Outra ação importante nesse sentido é o aprendizado do idioma do nativo e a tradução do Evangelho para facilitar a aproximação e o entendimento.

Com os negros, o processo foi menos dedicado, e o colonizador se limitou a proibir (ou reprimir) as práticas que considerava "feitiçarias", o que levou a processo adaptativo que historicamente se costumou chamar de "sincretismo": as entidades cultuadas nas religiões de matrizes africanas se disfarçam em santos católicos e são louvados em ocasiões aparentemente dedicadas aos santos cristãos. Os negros desenvolveram, então, sofisticadas formas de práticas religiosas que até hoje confundem e intrigam os estudiosos.

Não se pode ignorar o caráter predominantemente matriarcal de comunidades tradicionais e a acomodação dos discursos da igreja católica, a exemplo do culto pagão à Grande Mãe metamorfoseado na Virgem Maria e suas inúmeras variações. Nossa Senhora de Sant'Ana, avó de Cristo, representa também essa imagem de mulher que cuida e protege. Dos orixás femininos, por ser representado por uma mulher velha, Sant'Ana é sincretizada com Nanã.

Diante desse caldeamento cultural, novos textos vão surgindo, convergências de práticas e símbolos de vários lugares, que vão fazer sentido a esse povo mestiço e que transita por diversas teias de signos. Assim, o catolicismo popular vai incorporando tantos discursos quanto necessários para atender às demandas da fé de um povo que necessita de auxílio divino, já que os poderes públicos cumprem muito mal o seu papel. Situados em uma cultura de fronteiras, os sujeitos mestiçados culturalmente resolvem os dilemas das contradições do discurso dominante, sem se preocupar com embates. Essa preocupação é dos poderosos, dos que pretendem ser hegemônicos.

Assim como houve a tradução dos mitos indígenas para o português, grande parte da herança cultural africana nos foi transmitida pelos escravizados na língua dos senhores e adequada ao seu sistema de signos. Houve assim a tradução linguística e cultural. $\mathrm{O}$ que às vezes parece sincretismo é, na verdade, a sobreposição de imagens, como as Santas Anas. Por isso o culto a Santa Ana Defunta e a festa católica para Nossa Senhora de Sant'Ana convivem. 
O martírio da escrava decalca as narrativas de santos cristãos adaptadas à situação social do Brasil do tempo do cativeiro. É curiosa a semelhança com a narrativa do Negrinho do Pastoreio, um menino escravo que também é colocado sobre um formigueiro e socorrido por Nossa Senhora, sua madrinha que o protege. As narrativas da Senhora da Boa Morte da Irmandade do mesmo nome em Cachoeira, Bahia, fazem menção à Senhora da Boa Morte como uma filha de senhor de Engenho que ajudava os escravos e que, por sua bondade, virou santa e subiu aos céus de corpo e alma. Em todas essas narrativas, o contexto colonial escravagista se apresenta como pano de fundo dando suporte para a convergência do martírio dos santos com a salvação dos escravos.

Também o motivo dos contos populares da árvore mágica sobre o túmulo está presente na narrativa da Escrava. O pé de juá, plantado pelo filho, possivelmente para marcar o lugar, representa a transformação do corpo da mãe em outro ser, a árvore, também cultuada. Aqui a relação com as religiões de matriz africana fica ainda mais evidente. O solo onde estaria enterrada a santa é um solo sagrado, daí a resistência ao traslado da capela para outro lugar. Um truque comum usado pelos jesuítas para construir a sede de suas missões, igrejas e conventos era colocar a imagem de um santo em lugar apropriado e divulgar o boato do seu achamento naquele sítio, ao acaso, porque seria desejo do santo que ali fosse construída a igreja em sua homenagem. Assim, em vários locais do Brasil foram feitas capelas "por desejo do santo". Não sem razão, esse mesmo motivo se repete na história da Escrava Ana.

Esses textos vão se cruzando e entrecruzando, criando novos textos e novos sentidos. A coesão conseguida para as novas narrativas só é possível porque segue a mesma estrutura das narrativas tradicionais como os contos de exemplo ou de encantamento. São textos de cultura que se aproximam, a partir do que eles têm em comum, ou universal, para então se reorganizar: o que é periférico, os detalhes, as brechas para a criação. Nos contos de encantamento ou de magia, a heroína passa por provações e chega a um final feliz graças à intervenção da magia e do sobrenatural. Nos contos de exemplo e religiosos, o mal é punido e o bem recompensado dentro de um padrão ético cristão. A narrativa da Escrava Ana se encaixa nesses padrões e perpetua uma forma consolidada na tradição, somando-se a eles o texto bíblico e as hagiografias.

$\mathrm{Na}$ história da Escrava Ana, o discurso bíblico é ressignificado para atender aos fiéis que se identificam com a Santa Escrava, com o seu sofrimento e, ao mesmo tempo, veem na sua consagração uma recompensa, como nos contos populares acima citados. Se o catolicismo oficial tenta acomodar as injustiças sociais e o sofrimento por elas causados como necessários para a purgação dos pecados, oferecendo aos convertidos exemplos de santos que alcançaram a salvação e o reino dos céus tendo seu corpo martirizado, os oprimidos também vão santificando corpos negros abusados e transformando o sofrimento de seu povo em glória. Os beatos e santos populares são sempre milagrosos, independente do reconhecimento da Igreja, porque ouvem as promessas dos fiéis e estão ali bem pertinho deles. As promessas sussurradas para a Escrava Ana chegam mais rápido ao destino do que as preces a Senhora de Sant'Ana. A visita ao túmulo da mártir surte um efeito mais concreto de alívio e renovação da esperança porque há o testemunho da comunidade, não só de seu martírio como de seus milagres. O testemunho, palavra empenhada dos antepassados, muitas vezes parentes próximos, dão veracidade e confiança à narrativa e à Santa. E quem é essa Sant'Ana, avó de Cristo, que ninguém nunca viu? Cabe à igreja católica o esforço para sobrepor a história de Nossa Senhora de Sant'Ana à da Santa Escrava. A convivência é conveniente até o ponto em que o discurso popular não suplantar o oficial. A igreja aceita enquanto a Escrava permanecer nas margens, circunscrita a um espaço delimitado e não disputando com a outra sua hegemonia.

Há a convivência, mas haverá sempre uma tensão. Isso porque as narrativas populares que tratam da questão do negro, e também do índio ou mestiço, apresentam "modelos" que 
dão a medida de como a comunidade se autoorganiza e estrutura o seu meio social, conservando um código recebido e assimilado na cadeia de transmissão. Não de forma literal, mas distorcida, essas narrativas representam a aceitação social e como se dá essa aceitação. São esses traços do catolicismo popular que as narrativas revelam de forma contundente e que serão detalhadas adiante.

\title{
4 As narrativas
}

Ana, a escrava, conforme vamos deduzindo da narrativa de Dona Dove, foi a representação escolhida do Sagrado para a população pobre, que vivia basicamente da agricultura, no povoado periférico da Barriguda. A escrava trazia traços da identidade dessas pessoas, com parte delas sendo negras, vulneráveis pelas condições socioeconômicas, à margem dos sistemas de produção, subalternizadas. A Santa escrava passou a ser alvo dos pedidos, das promessas, das súplicas, porque além de ter sido castigada pelo seu Senhor, conhecia os martírios e o sofrimento daquela gente, castigadas pelas circunstâncias em que viviam. Além da fé, a Ana pobre e escravizada lhes concedeu uma espécie de valoração, haja vista que pessoas de outros lugares passaram a reconhecer a sua Santidade. A população da Barriguda passou a ter algo para chamar de seu. Foram elevados à categoria de terra da Santa Ana ou Defunt'Ana, como também era conhecida. Ana Fani Carlos relata que,

\begin{abstract}
toda memória coletiva tem por suporte um grupo limitado no espaço e no tempo, portanto uma memória dividida - real ou fictícia - propicia a coesão de um grupo e, em conseqüência, cria a integração. Um grupo que só se pode visualizar num espaço onde elementos da sua história estão presentes. Cada grupo definido localmente tem a própria memória e uma representação do tempo que é só dele. Ocorre que cidades provinciais se fundem em uma nova unidade enquanto o tempo comum se amplia. Esse fato nos colocaria diante de uma nova dimensão da relação entre a constituição da identidade e das relações do indivíduo com o espaço e o tempo. (CARLOS, 2007, p. 48)
\end{abstract}

Ao dialogar com outros habitantes dessa localidade sobre essa narrativa, percebo a relação de identidade dessas pessoas, construída em torno da história. O túmulo da escrava ainda existe e frequentemente é visitado e cuidado. Segundo Dona Dove, a sepultura dela era mais atrás, onde era o cruzeiro velho, o menor. Depois, a neta de Silas fez promessa e construiu aquela sepultura grande. Aquele cruzeiro grande é mais novo, mas o pé de juá é do tempo dela. Foi plantado naquele tempo. Para ter acesso ao túmulo, é preciso abrir uma porteira que fica ao lado da estrada que leva ao povoado e caminhar por dentro da vegetação. Mas a limpeza da trilha é feita com frequência, e as pessoas exigem do poder público que sejam removidas as pedras com máquinas e que as estradas sejam melhoradas, na época das chuvas. A preservação do lugar ajuda a manter viva a memória. E parece um sentimento coletivo essa manutenção do lugar, de forma tal que quem visita o túmulo da Santa, limpo, com velas e flores postas, parece perder um pouco a noção do tempo decorrido e compreender que a história é real, imaginando o caminho percorrido pelo filho de Ana para levá-la até aquele lugar, tentando desvelar o lugar do seu martírio.

Em contraponto, a Igreja Católica, ao que parece, procurou dissuadir a crença na figura da escrava pobre e negra e, em seu lugar, ofereceu aos seus devotos a figura consolidada de outra Ana, Santa legitimada, com uma aparência que em nada lembra a figura imaginária da escrava: Nossa Senhora de Sant'Ana, a avó de Jesus. Dona Dove relata que uma capela foi construída como pagamento de promessa a Santa Ana (a escrava), próximo ao seu túmulo. Ninguém sabe quando, nem qual foi o Pároco, mas um Padre que rezava as missas na Barriguda levou uma imagem de Nossa Senhora Sant'Ana para a pequena capela. Uma figura que em nada lembrava a cor e a aparência que imaginamos da escrava, que 
morreu por ter engravidado sem constituir família, sem sequer apontar a identidade do pai do seu filho. A imagem levada era da Santa Ana representativa da Sagrada Família. Um símbolo da Igreja e da hegemonia sobre os seus fiéis. E sem que se lembrem o espaço do tempo em que foram se dando essas transformações, num certo dia, a Igreja instituiu que a festa em comemoração à Santa seria na data de 26 de julho, mesmo dia em que se comemora Nossa Senhora de Sant'Ana, no calendário católico, embora para a comunidade, nessa data, eles celebrem a Santa Escrava. Sobre o altar da pequena igreja, está depositado um quadro de Nossa Senhora de Sant'Ana, em sua aparência angelical, branca, de cabelos lisos, com uma espécie de manto sagrado lhe cobre a cabeça. Mas nenhuma representação foi feita em pintura ou escultura para a Ana cujos restos mortais supõem que um dia estiveram depositados na sepultura que fica aos fundos da capela.

Percebe-se que as Santas Anas se misturam na mesma igreja, nos mesmos festejos, mas não se confundem. A comunidade celebra a Ana que sumiu da sepultura e se materializou numa imagem reluzente. É para ela que são devotadas as promessas, os fogos e as homenagens. Na última festa da padroeira da Barriguda ocorrida em julho do ano passado, entrevistei a minha própria mãe, Maria Ricardina (68 anos, pedagoga aposentada), sobre a condução da missa pelo Padre. Perguntei: qual Ana foi reverenciada na missa celebrada? Sobre qual delas a Igreja falou em seus ritos? E ela me respondeu: a missa foi de Nossa Senhora de Sant'Ana, mas o Padre falou da importância de preservar a história da Santa Ana. Disse que a comunidade não poderia deixar morrer o que aconteceu com a escrava e que tinham que registrar a história. Pediu para contarem a história na missa e uma pessoa contou.

Esse cenário faz ressurgir questionamentos que se relacionam aos sentidos criados pelos habitantes do lugar para as diferentes Anas. Sobre a (re)existência da Ana vulnerável, o polo mais fragilizado no jogo de poder que se sustém. Sobre qual das Anas traz o reflexo da identidade da população local, também periférica e marginalizada. E sobre a luta travada para preservar a imagem da Escrava, existente apenas no imaginário das pessoas, em contraponto a imagem institucionalizada, registrada nos livros sagrados e nas esculturas. Considerando Michel Foucault, quando diz que

Qualquer luta é sempre resistência dentro da própria rede do poder, teia que se alastra por toda a sociedade e a que ninguém pode escapar: ele está sempre presente e se exerce como uma multiplicidade de relações de forças. E como onde há poder, há resistência, não existe propriamente o lugar da resistência, mas pontos móveis e transitórios que também se distribuem por toda a estrutura social. (FOUCAULT, 2014, p. 18)

Notamos que, se de um lado, a Igreja impõe a sua doutrinação à Santa Católica, por outro, a comunidade, aparentemente passiva e sem resistir, permitindo que modifiquem o altar da Ana que lhes pertence, que lhe mostrem uma nova face, na verdade, resiste. Como afirma Stuart Hall,

Creio que há uma luta contínua e necessariamente irregular e desigual, por parte da cultura dominante, no sentido de desorganizar e reorganizar constantemente a cultura popular; para cercá-la e confinar suas definições e formas dentro de uma gama mais abrangente de formas dominantes. Há pontos de resistência e também momentos de superação. Esta é a dialética da luta cultural. Na atualidade essa luta é contínua e ocorre nas linhas complexas da resistência e da aceitação, da recusa e da capitulação, que transformam o campo da cultura em uma espécie de campo de batalha permanente, onde não se obtém vitórias definitivas, mas onde há sempre posições estratégicas a serem conquistadas ou perdidas. (HALL, 2003, p. 255)

A memória da Escrava, que não tem imagem, nem qualquer menção nas escrituras sagradas, que não tem rosto materializado em qualquer representação, permanece na memória 
coletiva. Essa memória tem selecionado aquilo que elege como representativo da sua identidade e aquilo que deseja não mais fazer parte. A Santa escrava foi escolhida como parte dos significados construídos para as pessoas desse lugar, como parte das suas referências. Percebo que essa sobrevivência assegurada pela oralidade tem mantido o túmulo e a capela (representativos da materialização da história), no mesmo lugar. São os símbolos palpáveis, ainda que a capela seja dividida com a outra Santa. Como se fossem posições estratégicas tomadas, para que a Santa Escrava prossiga em sua existência. Para que permaneça proclamando a Barriguda como solo sagrado.

Outro episódio que me chamou a atenção foi quando Dona Dove relatou que há algum tempo um Padre queria construir a capela em outro terreno, que fora doado. Narra, então, que a comunidade ficou dividida. Uns queriam a nova capela e outros disseram que não, pois a igreja tinha que continuar próximo ao local onde a Escrava fora enterrada. Os argumentos da instituição católica se fundamentaram na dificuldade de acesso ao lugar onde a pequena igreja fora construída, já que para chegar até ela era preciso adentrar no mato (que é sempre limpo) e que era preciso de mais espaço e de um local mais centralizado. Ressalto que esse acesso referido é de poucos metros, o caminho não é íngreme e depois de me deslocar tantas vezes para esse local, considero o acesso com um grau de dificuldade bastante reduzido. Perguntei a Dona Dove e a sua filha, que estava ao seu lado enquanto ela nos contava esses fatos, sobre o que achavam dessa construção proposta. Ambas disseram que se uma nova igreja fosse construída, distante do túmulo de Ana, a história poderia ser esquecida. Revelaram temer pelo desaparecimento de tudo aquilo que ouviram sobre a Santa e foi Dona Dove que concluiu dizendo que a história pode acabar. O impasse foi resolvido com a maioria da comunidade tendo optado pela continuidade da igreja no mesmo lugar.

\section{Considerações finais}

O que pude perceber ao tentar montar um panorama do que ouvi e observei nos relatos colhidos, foi que a Igreja Católica esteve presente desde o início da história da Santa Ana. Cabe lembrar que, segundo a narrativa, foi o próprio padre quem disse ao filho da Escrava que a sua mãe havia se transformado em uma Santa. Foi pelas mãos do mesmo Padre que, segundo contam, a imagem da Santa materializada, foi levada do local onde apareceu. O Padre foi quem solucionou o mistério do sumiço da Escrava Ana, foi quem lhe atribuiu a Santidade.

Mais tarde, a Igreja Católica volta a cena, introduzindo Nossa Senhora de Sant'Ana na capela construída para a outra Santa. Através da Igreja é que se dá a sua imposição enquanto a Santidade a ser celebrada na Barriguda, colocando-a na posição suprema de padroeira da festa. Mais tarde, a tentativa de modificar o local onde estava situada a capela, sugerindo a construção de uma nova Igreja, longe do túmulo da Escrava, distanciando-se dessa referência. Esses fatos dão a impressão de terem ocorrido para provocar o apagamento da figura da Santa Escrava. Ou para, quem sabe, tentar reduzir a sua importância num terreno fértil para a crença crescente. A Igreja continuou o seu papel de colonizadora, continuou com a missão catequizadora que desempenhou, desde a época em que o vale do São Francisco começou a ser desbravado. Continuou introduzindo os seus ritos, os seus Santos, o seu calendário na comunidade periférica, que precisava ser norteada. A avó de Jesus, a escultura da Santa angelical, a escolha da data da comemoração foram alguns dos elementos trazidos ao cenário da Barriguda, para reforçar os ditames que deveriam ser seguidos. Os párocos seguiram a sua missão, enquanto, em paralelo, as vozes do lugar continuaram propagando a Escrava, como a figura para onde convergiam as suas preces, promessas e devoção.

Michel Foucault diz que a verdade está circularmente ligada a sistemas de poder, que a produzem e apoiam e a efeitos de poder que ela induz e que a reproduzem (FOUCAULT, 
2010, p. 54). A Igreja, por sua posição hegemônica, procurou instituir a sua verdade entre os moradores do povoado, ao tentar infiltrar os seus próprios símbolos, em meio a crença da Defunt'Ana. Mas não encontrou eco na verdade anunciada. Ou a reprodução não se deu unicamente com a verdade proposta. A voz que anunciava o símbolo que a comunidade elegeu como representativo da sua identidade continuou sendo reproduzida. A verdade construída na subalternidade, na figura menor de uma escrava, na projeção de um igual.

Mas o poder da instituição católica continuou se sobrepondo, haja vista que não houve recusa à Nossa Senhora de Sant'Ana nos rituais, nem rejeição à imagem, ou à sua atribuição como a Santa Padroeira. Nos anúncios das festividades do dia 26 de julho, os Padres continuaram anunciando a festa em comemoração a Nossa Senhora de Sant'Ana. Nas pregações das missas, os louvores e os cantos continuaram sendo a ela dirigidos. As pessoas da localidade não questionaram a verdade pregada pelos religiosos católicos. Mas também não apagaram da memória individual ou coletiva a verdade que tomaram para si. Ao que parece, os símbolos católicos foram utilizados para reforçar essa memória. Dessa forma, o cruzeiro ao lado do túmulo, a escultura da Santa, que o Padre levou, reproduzida no imaginário das pessoas e a capela, reforçam a materialização da Santa Escrava. Os símbolos utilizados nos rituais católicos ajudaram a construir a parte mais real dessa história. Mas, mesmo a Igreja difundindo a festa celebrada a um dos seus Santos, os habitantes da Barriguda falam da festa da Escrava Ana. É a ela que celebram, acompanhando a missa. Há aqueles que também celebram as duas Santas. Não se percebe nenhum incômodo com o evento que é divulgado pelos Padres, diferente daquele que existe no imaginário coletivo. O que há é uma relação de convivência com as duas crenças.

As Santas Anas reproduzem as relações travadas no meio social da Barriguda e os processos identitários. As relações entre dominadores e dominados e os mecanismos utilizados para resistir. Nesse contexto visualizamos as marcas do colonizador, do poder, representado pela Igreja. A Santa Ana da Igreja Católica é a rainha da festa, a que ganha projeção na verdade pregada pelos Padres, a que está representada sobre o altar, a figura suprema. A Santa Ana da comunidade está debaixo do túmulo que se avista nos fundos da capela, sem rosto, nem feição material, sem representação no altar. Mas é essa Ana, que está posta no altar sagrado da memória, sem suporte escrito, sem microfones, nem leituras feitas por autoridades religiosas. É essa Ana, aparentemente mais vulnerável, que gerou a necessidade da outra Ana ser apresentada à comunidade. A Ana frágil cria, de certa forma, um sentido para a Ana hegemônica. As duas se posicionam como num jogo de forças. Uma é poder, a outra é resistência.

\section{REFERÊNCIAS}

CARLOS, A. F. A. O lugar do/no mundo. São Paulo: FFCH, 2007.

FOUCAULT, M. Microfísica do Poder. Rio de Janeiro. Paz e Terra, 2015.

GEERTZ, C. A interpretação das culturas - 1. ed., IS. reimpr. - Rio de Janeiro. LTC, 2008.

HALL, S. Da diáspora: Identidades e Mediações culturais. Belo Horizonte: UFMG, 2008.

ZUMTHOR, P. Introdução à Poesia Oral. Belo Horizonte: Ed. UFMG, 2010. 